\title{
Analysis of current problem state in teaching of Computer science and information and communication technologies to higher education students
}

\author{
Andrey Gazizov ${ }^{1, *}$, Evgeny Gazizov ${ }^{2}$, Svetlana Gazizova ${ }^{3}$, and Vera Petrova ${ }^{4}$ \\ ${ }^{1}$ Don State Technical University, Gagarin sq., 1, 344003 Rostov on Don, Russia \\ ${ }^{2}$ Kazan state agrarian University, 65 K. Marx str., 420015 Kazan, Russia \\ ${ }^{3}$ Kazan (Volga region) Federal University, 18 Kremlevskaya str., 420008 Kazan, Russia \\ ${ }^{4}$ South Federal University, 105/42 B. Sadovaya str., 344006 Rostov-on-Don, Russia
}

\begin{abstract}
The article shows different aspects of teaching the subject «Computer science» to the pedagogues-psychologists students according to education standard of Russian Federation. The analysis of teaching the subject to students of technical and humanities universities is carried out. Also the article lists number of skills that students of humanities should get as the result of «Computer science» learning.
\end{abstract}

\section{Necessity and relevance of training specialists in the field of informatics and information and communication technologies}

National educational doctrine of Russian Federation defines that «the educational system is aimed at: teaching highly-educated and highly-qualified workers, able to professional growth and mobility in the conditions of society informatization and new high-tech development».

Significance of teaching specialists, who are able to use effectively and knowingly modern information and communication technologies in the professional field, in the conditions of globalization and society informatization gains special interest.

Place and role of informational teaching subjects for students in educational programmes entirety are determined by their goals, tasks, functions and the results of their realization in university actual practice. On the basis of educational system's strategic goals, stated in National educational doctrine of Russian Federation, Kolin K. K. emphasizes the most important ones [1-3]:

- formation of new informational culture of Russian society in new highly-automated informational human environment in XXI century;

- teaching highly-qualified specialists, able to professional growth and mobility in the conditions of society informatization and new high-tech development.

Thuswise, successfulness of future specialist in any professional field will depend on how well he has the following skills formed: to find, to classify, to present information through different ways, to orientate in growing data flotation [4-17]. Realization of recited technologies

\footnotetext{
* Corresponding author: gazandre@yandex.ru
} 
and skills formation of information operating in the system of high education is carried out in terms of informational teaching.

As well as Kozlov. O. A., we determine informational teaching as essencial component of educational process, which is directed on specialists teaching, able to use effectively information and communication technologies in the process of its professional activities.

Issues of theory and informational teaching methodology are reviewed in the research works of Branskiy Yu. S., Denisova A. L., Zaynutdinova L. Kh., Kozlov O. A., Kuznetsov A.A., Lobach O. V., Lun'kova E. Yu., Rakitina E. A., where it is mentioned that the system of high education must carry out proactive student teaching in the sphere of information and communication technology using in its professional activity.

Currently the course «Computer science» is penetrated as comprehensible subject for technical degrees, as well as for humanities.

The main aim of computer science comprehensible subject is training a specialist for living within informational society, formation of fundamental knowledge in subject category «Computer science», which consist of common knowledge about information, types of informational resources, kinds of informational activities, principles of computer functioning, algorithms, informational modelling, using information and communication technologies. Moreover, learning of basic general informational technologies is specified, processing of text, numerical and image information, operating with databases and spreadsheets and basis of communications. Presently the complex of these knowledge is viewed as part of whole human culture and is called informational culture. A graduate, who has studied the course of computer science, according to Rakitina E. A., must:

- understand principles and features of informational process running in the professional activity;

- know characteristics of professionally important information;

- have a knowledge about basic principles of informational systems, which are used in a professional activity, and skills of operating with these systems;

- have a formed necessity in using information and communication technologies while solving professional tasks, based on conscious proficiency of informational technologies.

We are going to carry out an analysis of university students teaching state in the sphere of computer science and information and communication technologies.

As Morar' E. V. mentions in his research, few paradigms have changed for a short period of learning computer science by students. Each of the paradigms applied its amendments into the methodical system of computer science teaching. On the first stage of the subject establishment the algorithmic approach was predominant, the main thesis of which - «soft engineering is the second competence», was suggested by Ershov A. P. On the second stage the usage of computer as a tool for problem solving becomes centre-stage (instrumental approach). In the meantime widely used in today's life term «informational technologies» was created.

Current stage is characterised by realization of computer science course role, which gives a great imput in the formation of scientific worldview (worldview approach), development of comprehensible skills for operating with information and students training for professional activity.

Such dynamics of change of paradigms teaching computer science, according to the author, is defined markedly with changeability of computer science content due to constant upgrade of hardware and software resources.

Kolin K.K., analysing the content of the computer science course, notes that rather high knowledge is given in technical universities in the field of technical, software and information support of computer science, computer and telecommunication systems, as well as in the field of new information technologies. Humanities universities, generally, are oriented on gaining «computer competence», in other words basic knowledges and skills in the sphere of modern computing tools and telecommunication system usage. It's important to say that teaching 
computer science subject to students of humanities universities has its peculiarities. The main one consists in rather low level of student school training. Due to these principle tasks of computer science and information and communication technologies humanities are renewal of knowledge, perceived in the course of secondary education, necessary for preparing for the study of special subjects, as well as increasing the general level of students' culture, forming their modern ideas about the information picture of the world.

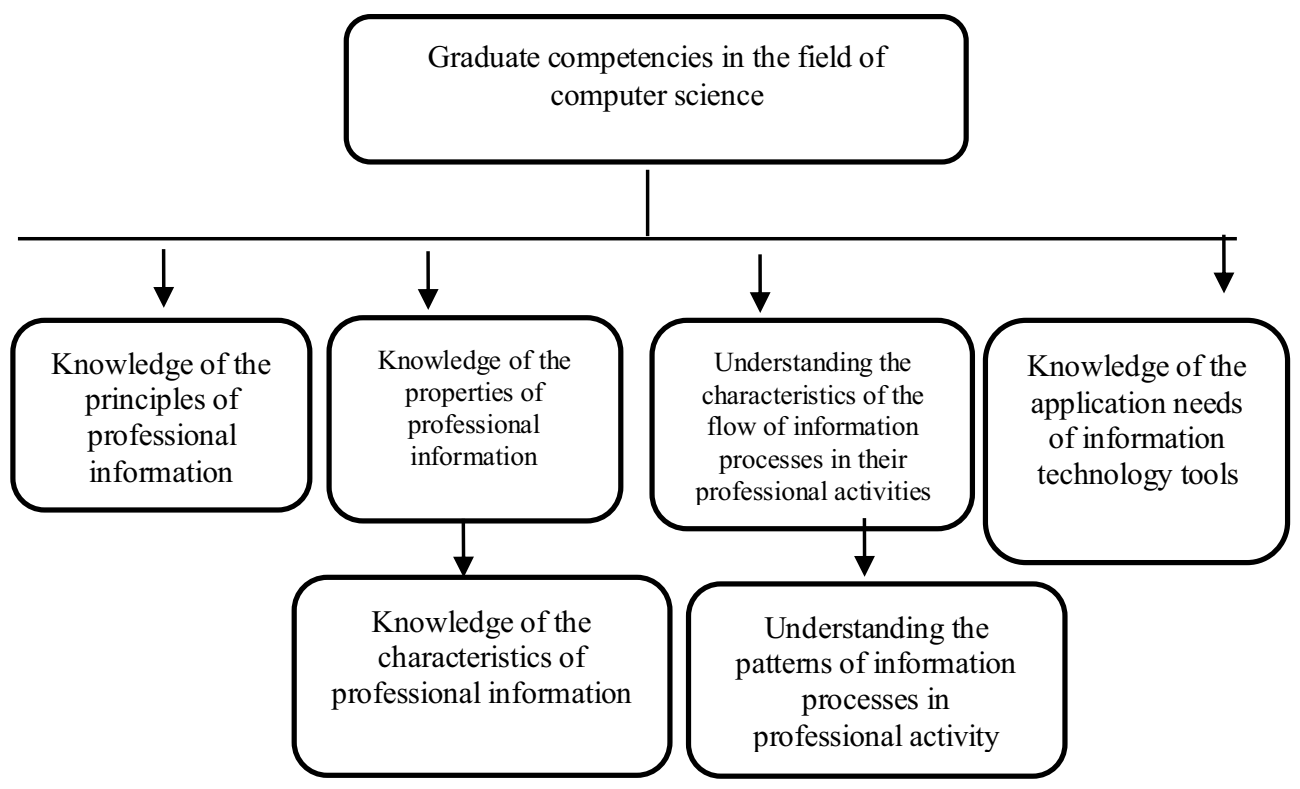

Fig. 1. Graduate competencies in the field of computer science.

\section{Analysis of the methods of teaching computer science to students of humanitarian specialties of universities}

Now we are going to look at methods of computer science teaching to students of humanities. Among research works, dedicated to methodical approaches for students informational teaching psychological-pedagogical and other schools of Russian universities and solutions shown above, we can define following studies: Klueva E. V. (for invariant and variant activity components), Smetannikov A. L. (on the basis of informational modelling elements in the content of teaching software designing for learning goals); Smolyaninova O. G. (for usage of case-study, on the basis of real situation modelling); Kitaevskaya T. Yu. (formation of differentiated content by using computer-oriented technologies), Shtirov A. V. (professional teaching modelling via didactic computer environment) etc.

We'd like to emphasize that evolving of students informational teaching in psychologicalpedagogical faculties and other humanities is based on improving not just organization and content, but also usage of modern training resources in the educational process. There are following tendencies in the modern training resources development [16]:

- the growth of computer training tools importance in the educational process;

- the Internet as mass-communicational tool brings great influence on the changing of educational content and formation of unique educational system.

We'd also like to mention that creation of computer training tools abroad generally is directed to maintain project teaching and binary lessons (there is no independent computer 
science subject). Computer training tools come into effect as educational multimedia-products: from edutainment (educational entertainment) to education its self, resided on CDs or directly on the Internet.

Web-technologies gained special popularity in the sphere of education. Their main advantages are [15]:

- possibility of giving more time for student engagement on individual classes;

- disposal from numerous repetition of learning activities;

- providing improvement of teaching and learning aids quality.

Multimedia and Web-technologies allow students to master course content in any form: imagery, sound, video, animation. World Wide Web and Internet-technologies, which support that service, form new content for communication. Internet is one of the greatest educational digital resources. Educational digital resource is defined as a complex of digital training resources, which are necessary and sufficient for providing educational process in the course of methodical educational system [12].

Denisova A. L., by studying methodical theoretical bases for informational technologies using during students teaching, makes analysis of informational activity according to following tendencies: information-valuable, information-operative, information-temporal.

However, teachers of computer science subjects distinguish following issues: firstly, students of humanities enter university, having different levels of training and interest for computer usage in their future profession; secondly, there is low usage of information and communication technologies for professional tasks solving.

Now we are going to review world tendencies for computer science and informational technologies teaching. In the 80 s practical adoption of new informational technologies in teaching different subjects started in schools, colleges, universities and educational departments of economically developed countries, such as USA, Japan, France, England. However, the training of future workers in the field of computer science was oriented on learning of computer science fundamental bases. Algorithmic-programming approach was predominant in teaching.

Today another training programme of information scientists is developing - teaching of computer science practical aspects and methods of new informational technologies usage in teaching certain academic subject [13].

Block-modular structure of curriculum organization is practised in the process of computer science teaching in many country's development. Three levels of educational programmes are suggested: basic, intermediate and advanced. Advanced and extra programmes are given to students of last educational stage and offer deeper and wider learning of necessary alreadylearnt topics or extra specialised topics which will take place in student's future career.

\section{Analysis of the methodology of teaching computer science to students abroad}

Today, USA departments carry out studies to find optimal ways for restructure and content change of academic subjects on the basis of new educational principles and models, which is described in the concepts of task-oriented education, practical thinking formation and development, lifelong learning. The problem of fundamental knowledge unimportance (including computer science) has come into sharp focus, and that requires new approached for teaching of students in the sphere of computer science and informational technologies.

There was established scientific consortium in Great Britain. It offers special education for putting information and communication technologies into professional psychologicalpedagogical activity. Subjects, offered by the consortium, form informational teaching, which consists of following modules: getting basic knowledge about studied science, information accumulation and use, analysis and interpretation of collected information, modelling in science, individual skills development [17]. 
The same tendencies are also characterized for Japan. There is a strict division between teaching computer science and new informational technologies in the high education system of Japan. The principle educational content is fundamental aspects of computer science only for the universities' faculties, which train computer science theorists, designers of microprocessor technology and informational technologies means, software and application programmers. In the content of training for other faculties, educational aspect is directed to new information technologies teaching and new ways for their implement in future professional activity. A shift in training toward reorientation to the practical aspects of computer science and the information and communication technologies use in future professional activities is also characteristic for other countries.

Students should gain special knowledge and skills in information technologies using in the subject category of their future professions.

\section{Operation and content of teaching computer science and informational and communicational technologies to pedagogics and psychology students}

The process of education informatization is characterised by active information and communication technologies usage of all specialists who work in educational sphere, including pedagogues and psychologists.

An analysis of studies on the training of teachers in the field of computer science and information and communication technologies shows that one of the main reasons that hinder their appropriate use in professional activities is the lack of training in that sphere. In this regard, the problem of training pedagogues and psychologists in the use of information and communication technologies in professional activities, the solution of which will help to improve the educational process, is very relevant.

The need to prepare a pedagogue-psychologist to information and communication technologies in professional activities is reflected in the State Educational Standards of Higher Professional Education, specialty 030301 "Psychology" in the discipline of the block EN "Computer Science in Psychology" (100 hours). Due to the regional component of SES HPE, the subject "Social Computer science" can be introduced (in particular, this is implemented at Cherepovets State University).

The subject «Computer Science in Psychology» is learnt by first-year students. Its purpose is to form a student with a holistic knowledge of computer science, its role in the society's development, to reveal the essence and capabilities of the hardware and software of computer science; development of computer skills. As the result of subject learning, students must:

Know:

1. Function and organization of personal computer.

2. Notion of formalization, algorithmization and programming.

3. Assignment of office applications.

4. Possibility of digital databases usage in psychology.

5. Assignment of computer networking and the Internet.

6. Internet psychological resources.

7. Possibility information security from unauthorised access and computer viruses.

8. Assignment of computer statistical systems.

Be able to:

1. Edit text via word processing programme.

2. Create calculation tables for analysis of experiment results.

3. Create and use databases for processing and search of necessary data.

4. Secure text documents, digital tables and databases from unauthorised access. 
5. Operate files and folders structure of Windows.

6. Check data for computer viruses.

7. Send e-mail messages.

8. Search for necessary information on the Internet.

Get skills of:

1. Working in word processing programme.

2. Working with digital tables.

3. Creating databases.

4. Searching for necessary data in the database.

5. Securing data from unauthorised access.

6. Checking data for computer viruses.

7. Searching for necessary working information on the Internet.

8. Sending e-mail messages.

Main units of subject «Computer Science in psychology» (according to State Educational Standard of Higher Education for speciality 030301 «Psychology») are:

- function and organization of personal computer;

- notions of formalization, algorithmization and programming;

- office applications; work with text;

- data security; computer networking;

- Internet;

- information search;

- Internet resources; digital databases;

- computer statistical systems.

Subject «Social computer science» is learnt by second-year students. Its goal is to define social computer science as science, which studies complex of issues, connected to carrying out of informational processes within society and its informatization; to teach how to represent knowledge for its further involvement into social informational potential; to form informational thinking. As the result of studied subject, students must:

Know:

1. Social computer science: object, line of research.

2. Notion of information technology

3. Connection of notions matter, energy, information, knowledge.

4. Correlation of notions information, data, knowledge.

5. Notion of social informational resource.

6. Notion of society national informational resource.

7. Notion of society informational environment.

8. Notion of society informational potential.

9. Notion of informational culture.

10. Notion of personal informational comfort.

11. Notion of information security.

12. Notion of information criminality.

13. Semantic bases of social computer science. Notion of informology as common information theory.

14. Knowledge formalization: methods and ways. Their efficiency, comparison study.

15. Information systems. Structure and classification of information systems. Assignment of databases.

16. Notion of artificial intelligence.

17. Expert systems: structure and classification.

18. Notion of computer virus and antiviral programme.

Be able to:

1. Sort necessary information for its sharing in the format of presentation; 
2. Create computer presentations, which include different ways of impormation representation: text, imagery, animation, sound information, hypertext, etc.; action targets, effects.

3. Create Web-pages on the basis of HTML. Public them on the Internet.

4. Check computer media for computer viruses. Disinfect virus-infected files.

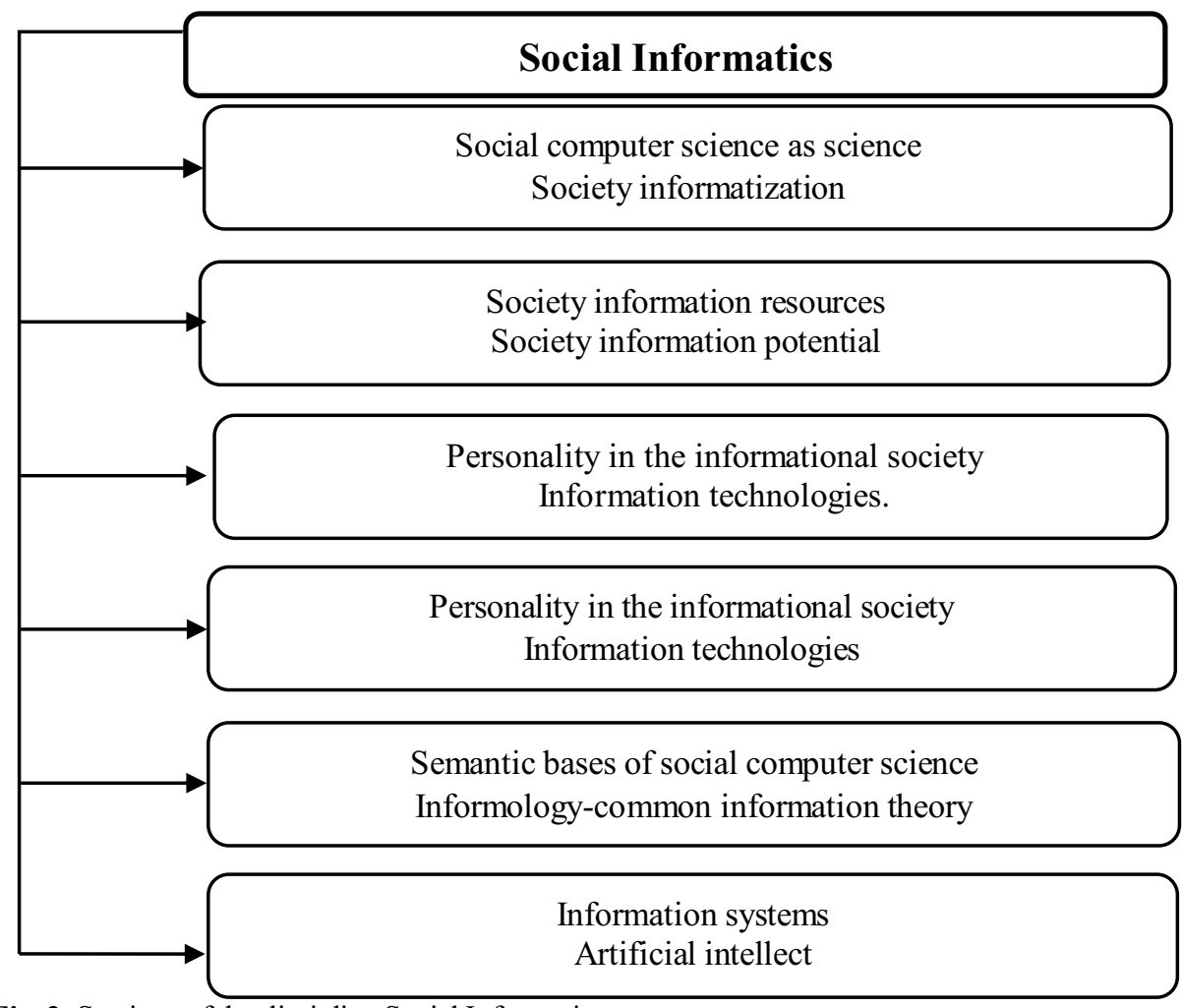

Fig. 2. Sections of the discipline Social Informatics.

Get practical skills of:

1. Creating interactive multimedia presentations.

2. Preparing Web-pages.

3. Checking computer media for computer viruses.

Main subject units of Social computer science:

1. Social computer science as science.

2. Society informatization.

3. Society information resources.

4. Society information potential

5. Personality in the informational society.

6. Information technologies.

7. Semantic bases of social computer science.

8. Informology-common information theory.

9. Information systems.

10. Artificial intellect.

\section{Conclusion and conclusion}


In conclusion, we'd like to mention, that offered subjects don't solve problems of teaching information and communication technologies usage in the professional activity to psychologists-pedagogues. Teaching in the course of subjects «Computer science in psychology» and «Social computer science» includes formation of common complex of knowledge and skills which don't provide commitment for professional activity in the conditions of modern informational environment. From our point of view, the problem consists in insufficient understanding of possibilities and peculiarities of information and communication technology usage in professional psychological-pedagogical activity.

Despite the fact that informational teaching is a necessary component of modern psychologist professional teaching, it can be noted that according to State Educational Standard of Higher Professional Education, time given to psychology-students for learning subjects of information curriculum is not enough for getting skills of information and communication technologies usage in the professional activity. There isn't value in information subjects teaching and special subjects of psychology-students.

To sum up, we may state that in the system of training teachers-psychologists in the field of computer science and IC, there is a gap between the objective requirements of the time for training teachers-psychologists who own information and communication technologies and the established practice of training teachers-psychologists in the field of computer science and ICT, which does not take into account potential possibilities of using ICT tools in psychodiagnostics, psychocorrection, psychoprophylaxis, psycho-counselling, psycho-education, as well as the specifics of the subject area of psychology.

An analysis of the organization and content of informational training of psychology teachers showed that there is a certain gap between the objective requirements of the time for informational training of psychology teachers who own ICT tools and traditional methodological approaches to teaching information cycle disciplines.

The analysis of information training allows us to highlight the levels of training of psychologists in the field of ICT tools in professional activities.

\section{References}

1. A. Khattab, K. Abdelgawad, Yelmarthi, Int. Conf. on Microelectr. (ICM), 201-204 (2016)

2. M. Dholu, K.A. Ghodinde, Int. Conf. on Trends in Electr. and Inform. (ICOEI), 339342 (2018)

3. M.R. Yousefi, A.M. Razdari, Int. J. of Advanc. Biolog. and Biomed. Res. 2(4), 473-476 (2014)

4. R. Inglés, P. Perek, M. Orlikowski, A. Napieralski, Mixed Design of Integrated Circuits \& Systems (MIXDES), 153-157 (2015)

5. G. Craessaerts, J. De Baerdemaeker, W. Saeys, Biosystems Engineering 106, 26-36 (2010)

6. D.D. Bochtis, C.G.C. Sørensen, P. Busato, Biosystems Engineering 126, 69-81 (2014)

7. Z. Zhai, J. Fernán Martínez, V. Beltran, N. Lucas Martínez, Computers and Electronics in Agriculture 170 (2020)

8. B. Drury, R. Fernandes, M.-F. Moura, A. de Andrade Lopes, Information Processing in Agriculture 6, 487-501 (2019)

9. H. El Bilali, M. Sadegh Allahyari, Information Processing in Agriculture 5, 456-464 (2018)

10. R. Miodragović, M. Tanasijević, Z. Mileusnić, P. Jovančić, Expert Systems with Applications 39, 8940-8946 (2012) 
11. D. Bochtis, C. Aage Gron Sorensen, D. Kateris, Operations Management in Agriculture, 79-115 (2019)

12. Ronkainen, IFAC Proceedings 46, 259-263 (2013)

13. Chen Chu, Zhao Zuo-xi, K.E. Xin-rong, Guo Yun-zhi, IFAC-PapersOnLine, 51, 346352 (2018)

14. J.W. Jones, J.M. Antle, B. Basso and others, Agricultural Systems 155, 269-288 (2017)

15. S. O’Neill Somers, L. Stapleton, IFAC-PapersOnLine 48, 213-218 (2015)

16. E3S Web of Conferences 175, 05004 (2020) doi: 10.1051/e3sconf/202017505004 